Marquette University

e-Publications@Marquette

College of Nursing Faculty Research and

Publications

Nursing, College of

$1-2019$

\title{
The impact of maternal BMI, gestational weight gain, and breastfeeding on early childhood weight: Analysis of a statewide WIC dataset
}

Jennifer M. Ohlendorf

Marquette University, jennifer.ohlendorf@marquette.edu

Karen Marie Robinson

Marquette University, karen.robinson@marquette.edu

Mauricio Garnier-Villarreal

Marquette University, mauricio.garniervillarreal@marquette.edu

Follow this and additional works at: https://epublications.marquette.edu/nursing_fac

Part of the Nursing Commons

\section{Recommended Citation}

Ohlendorf, Jennifer M.; Robinson, Karen Marie; and Garnier-Villarreal, Mauricio, "The impact of maternal BMI, gestational weight gain, and breastfeeding on early childhood weight: Analysis of a statewide WIC dataset" (2019). College of Nursing Faculty Research and Publications. 619.

https://epublications.marquette.edu/nursing_fac/619 
Marquette University

e-Publications@Marquette

\section{Nursing Faculty Research and Publications/College of Nursing}

This paper is NOT THE PUBLISHED VERSION; but the author's final, peer-reviewed manuscript. The published version may be accessed by following the link in the citation below.

Preventive Medicine, Vol. 118, (January 2019): 210-215. DOI. This article is (C Elsevier and permission has been granted for this version to appear in e-Publications@Marquette. Elsevier does not grant permission for this article to be further copied/distributed or hosted elsewhere without the express permission from Elsevier.

\section{The impact of maternal BMI, gestational weight gain, and breastfeeding on early childhood weight: Analysis of a statewide WIC dataset}

Jennifer M. Ohlendorf

Marquette University College of Nursing, Milwaukee, WI

Clinical Translational Science Institute, Medical College of Wisconsin, Milwaukee, WI

Karen Robinson

Marquette University College of Nursing, Milwaukee, WI

Mauricio Garnier-Villarreal

Marquette University College of Nursing, Milwaukee, WI

Highlights

-Pre-pregnancy BMI and gestational weight gain contribute to offspring obesity risk.

-Breastfeeding does not protect against the effects of these weight-related factors.

- Low-income maternal-child dyads are vulnerable to obesity and its health effects.

-Providers must find tailored ways to promote healthy weight among these mothers. 


\section{Abstract}

Early childhood obesity is a persistent health concern with more frequent and significant impact on low-income families. Maternal weight factors impact offspring weight status, but evidence on whether breastfeeding protects against this impact is mixed. This analysis examined a model to predict early childhood obesity risk, simultaneously accounting for maternal pre-pregnancy body mass index (BMI), gestational weight gain, and breastfeeding. The team analyzed 27,016 unique maternal-child dyadic records collected via the Supplemental Nutrition Program for Wisconsin Women, Infants, and Children (WIC) between 2009 and 2011. Generalized Linear Modeling, specifically logistic regression, was used to predict a child's risk of obesity given the mother's pre-pregnancy BMI, gestational weight gain, and duration of breastfeeding. For each $1 \mathrm{~kg} / \mathrm{m}^{2}$ increase in prepregnancy BMI, there was a $4.5 \%$ increase in risk of obesity compared to children with mothers of normal BMI. Children whose mothers had excessive gestational weight gain were $50 \%$ more likely to have obesity compared to those whose mothers had ideal weight gain. For each week of additional breastfeeding, there was a $1.9 \%$ increased risk of obesity. The risk models did not differ by race. In this model, accounting for pre-pregnancy weight, gestational weight gain, and breastfeeding among a diverse, low-income sample, women with prepregnancy overweight and obesity or who had excessive gestational weight gain had the highest risk of early childhood obesity. While breastfeeding is healthy for many reasons, providers should focus on maternal weightrelated behaviors when counseling mothers about how to avoid risk of early childhood obesity.

\section{Keywords}

Gestational weight gain, Breastfeeding, Weight, Early childhood obesity

\section{Introduction}

Obesity among young children has lifelong implications, thus early prevention of obesity remains a high priority. Preschool children with lower socioeconomic status (SES) are at higher risk for overweight and obesity and the associated lifespan health risks, including diabetes and heart disease (Centers for Disease Control and Prevention [CDC], 2013; Pulgaron 2013). Both rapid weight gain in infancy and overweight and obesity during the preschool years increase risk for being overweight or obese in adulthood (Andrea et al. 2017; CDC, 2013; Lamb et al. 2010; Shankaran et al. 2011).

In the United States, approximately $14 \%$ of preschool-aged children are obese. This rate is higher among African American (20.0\%) and Hispanic preschoolers (17.7\%) (CDC, 2013; Hales et al. 2017). Nationally, preschool obesity rates have decreased slightly. However, the state of Wisconsin has remained consistently above national preschool-age obesity averages, with $17 \%$ of children overweight and $14.7 \%$ obese (CDC, 2013 ).

Childhood overweight and obesity adds an additional \$14.1 billion in annual healthcare expenditures in the United States, due to extra outpatient visits, prescription drugs, emergency room visits, and extended lengths of stay for children who are hospitalized with obesity related comorbidities compared to those who are not obese (Pelone et al. 2012; Trasande and Chatterjee 2012). Children in low-income families are at a higher risk for overweight and obesity, increasing financial burden to families that can least afford it. Obese children also bear a lower psychosocial quality of life, due to stigma (Wallander et al. 2012). Efforts to prevent childhood obesity tailored to this population that experiences health disparities are a national health priority (U.S. Department of Health \& Human Services, 2014).

\subsection{Statement of the problem and literature review}

The causes of childhood overweight and obesity and subsequent risk for obesity-related chronic illness include factors beginning as early as the intrauterine environment, continuing through the first year of life and beyond (Norris et al., 2012; Margerison Zilko et al., 2010; Tomar et al. 2015). A complex interplay of genetic 
predisposition combined with influences on epigenetic expression-including intrauterine exposures to maternal overweight and obesity, gestational weight gain, and feeding practices in the early childhood periodall contribute to the development of childhood obesity and are opportunities for prevention (Langley-Evans 2014; van Dijk et al. 2015).

Known predictors of childhood overweight include: female gender, intrauterine diabetes exposure, large for gestational age at birth, shorter breastfeeding duration, and rapid infant weight gain (Gopinath et al. 2012; Goodell et al. 2009; Santos et al. 2009; Lamb et al. 2010). Maternal weight factors, such as pre-pregnancy obesity, as well as gestational weight gain that exceeds recommendations, have also been identified as contributing to childhood obesity (Kaar et al. 2014; Tie et al. 2014). Some studies have found that breastfeeding lowers risk of childhood obesity (Grummer-Strawn and Mei, 2004; Moss and Yeaton 2014; Umer et al. 2015). However, the evidence is mixed: systematic reviews of breastfeeding have determined that the evidence for lowering childhood obesity risk is limited by the quality of research and variations among vulnerable populations (Hess et al. 2015; Lefebvre and John 2014).

Among the body of evidence, only one study has examined the combined effects of maternal factors including pre-pregnancy weight status and gestational weight gain along with infant feeding choices, like breastfeeding initiation and duration, in relation to childhood risk of overweight. The study was limited in its generalizability as it included only children who had been identified as at risk for diabetes in its sample (Lamb et al. 2010). This study is unique in examining the relationships between all these variables in a more generalized sample of lowincome children.

Furthermore, there are limited studies that have examined race/ethnicity as it relates to the effects of prepregnancy weight status, gestational weight gain, and infant feeding choice. In a large retrospective cohort study, with an overall diverse sample. Heerman et al. (2014) found that pre-pregnancy obesity combined with excess gestational weight gained increased the likelihood of childhood obesity through the first year of life. The authors however, did not analyze the impact race may have had on childhood weight outcomes. This study will address this gap in understanding.

The aim of this research was to test the hypothesis that maternal pre-pregnancy weight status, gestational weight gain, maternal feeding choices and the weight status of the woman's offspring are interrelated. Specifically, the focus of this research is the relationship between these variables among women and children who participate in the Wisconsin WIC program in order to provide evidence for future targeted interventions for at risk women and children to reduce risk of unhealthy weight and its sequalae.

This study will help perinatal healthcare providers who have an opportunity to influence weight-related behaviors, including nutrition for the maternal-child dyad (Karnon et al. 2013; Streuling et al. 2010). As we better understand these modifiable factors and their contribution to weight-related risk to offspring, we can better plan interventions that can be delivered during pregnancy with the potential to influence multiple generations in a vulnerable population.

\section{Research questions}

1. What is the relationship between maternal pre-pregnancy body mass index (BMI), gestational weight gain and child overweight during the first 2 years of life?

2. Is the relationship between maternal pre-pregnancy BMI, gestational weight gain, and child overweight moderated by duration of breastfeeding?

3. Are there differences in the relationship between pre-pregnancy BMI, gestational weight gain, and child overweight based on race/ethnicity? 


\section{Methods}

\subsection{Design and sample}

This study was a retrospective correlational study. We analyzed the clinic visit records for 27,016 maternal-child dyads enrolled in the Wisconsin WIC program that were collected and reported for the Center for Disease Control and Prevention's Pregnancy Nutrition Surveillance Survey (PNSS) and the Pediatric Nutrition Surveillance Survey (PedNSS) between 2009 and 2011. The datasets contained a randomized code that was used to link the maternal record reported to the PNSS with the child record reported to the PedNSS. The data was provided to the research team directly from the Wisconsin WIC Program and was de-identified and encrypted by the research team for protection of privacy. Institutional Review Board approval was secured from the academic institution before conducting the research.

\subsection{Measures}

The outcome of interest for this study was early childhood obesity. Child obesity was classified as infants above the 95th percentile of weight-for-length at their chronological age using Centers for Disease Control and Prevention growth charts, up to age 2 years (McCormick et al. 2010; Ogden et al. 2014).

The independent (predictor) variables were represented by the following data points from the dataset: Weeks of breastfeeding, race/ethnicity, pre-pregnancy BMI, and gestational weight gain as reported to PNSS or PedNSS. The data were coded into one of 3 categories for analyses because gestational weight gain is meaningful only when categorized as: 1) less than recommended, 2) appropriate, or 3) excessive based on the woman's prepregnancy BMI using the Institute of Medicine $(\underline{\mathrm{IOM}, 2009)})$ guidelines.

\subsection{Analytic strategy}

Generalized linear modeling was used to analyze the data, specifically using logistic regression (Agresti 2007). Logistic regression specifies a model to predict binary data by the addition of the logit link; this way it predicts the increase/decrease in log-odds to score 1 in the binary outcome. The logit link function transforms continuous predicted values to the range of probabilities $[0,1]$. These log-odds are later transformed into odds ratio (OR) and probabilities for interpretation and presentation as effect sizes. The OR represents the multiplicative change in the odds of scoring 1 in the binary outcome variable. The results are presented as OR and probability increase/decrease of child overweight as multiple interpretations of the effect sizes, and with plots representing the expected change in probability in function the predictors (Agresti 2007; Gelman and Hill 2007).

To answer research questions 2 and 3, we tested the moderating/interaction effects by including the interaction between the predictors and the possible moderating variables. For research question 2, we tested if weeks of breastfeeding moderates any relation between predictor and outcome. For research question 3 , we tested if race/ethnicity moderated the other relations between predictor and outcome. These interactions were tested by probing and plotting, by both looking at the significance testing for the interaction, and plotting the change in the relations based on the moderating variables (Darlington and Hayes 2017).

The research team established an a priori plan to use Multiple Imputation (MI) to account for missing clinical data (Enders 2010; Rubin 1987; Baraldi and Enders 2010). Multiple Imputation allows for maintaining every subject in the data without losing power, while decreasing the possible bias of the estimates. For this project we used 100 imputations, which allowed for proper point estimates and for estimation of the standard error. Of the variables included in the analysis, weeks of breast-feeding and gestational weight gain are the ones with missing data, with $53.6 \%$ and $12.9 \%$ of missing values respectively. With $\mathrm{MI}$ the model presents the best estimates, accounting for variability due to missing data. 
Data analysis was done with the $\mathrm{R}$ platform ( $\mathrm{R}$ Core Team 2017). Multiple Imputation was performed using the $\mathrm{R}$ package, Amelia (Honaker et al. 2011). The results from the logistic regression on the imputations were combined with the R package, Zelig (Choirat et al. 2017).

\section{Results}

From the sample of 27,016 maternal-child dyads, 977 infants were categorized as obese, representing a $3.6 \%$ of the sample. Another 2291 infants were categorized as overweight (between the 85th and 95th percentile of weight-for-length-for-age), representing $8.5 \%$ of the sample. On average, mothers were overweight, with a mean $\mathrm{BMI}$ of 27.67 (SD = 7.07), and half of mothers had a higher than recommended gestational weight gain. On average, infants in the sample were small for age, with a mean weight-for-age percentile of 46.51 (SD = 29.14).

The number of children who were ever breastfed was $n=1,2519$, representing $46.34 \%$ of the sample. Among the breastfed children, 5716 (45.66\%) were above the 50th percentile of weight-for-age, and the mean duration of breastfeeding was 5.58 weeks (SD = 7.14). The sample was racially diverse and reflected the population of Wisconsin: $19.08 \%$ of the sample was African-American and $18.74 \%$ were Hispanic (Table 1).

Table 1. Sample descriptors.

\begin{tabular}{|l|l|l|}
\hline & Mean (SD) $\mathbf{n}=\mathbf{2 7 , 0 1 6}$ & Range \\
\hline Infant age & $1.72(2.11)$ & $0.0-11.83$ \\
\hline Mother age (years) & $25.07(5.60)$ & $12.0-53.0$ \\
\hline Pre-pregnancy BMI & $27.67(7.07)$ & $15.1-59.9$ \\
\hline Infant weight percentile & $46.51(29.14)$ & $0.0-99.9$ \\
\hline Weeks of breast feeding & $5.58(7.14)$ & $0.0-47.0$ \\
\hline \multicolumn{2}{|l|}{} & Percentage (\%) \\
\hline Infant obesity & 3.6 \\
\hline Infant sex: male & 50.49 \\
\hline Urban area & 52.22 \\
\hline Maternal weight gain & \multicolumn{2}{|l|}{} \\
\hline Ideal weight gain & 28.37 \\
\hline Less than ideal weight gain & 21.32 \\
\hline More than ideal weight gain & 50.31 \\
\hline Race/ethnicity & \multicolumn{2}{|l|}{} \\
\hline White & 52.82 \\
\hline Black & 19.08 \\
\hline Hispanic & 18.74 \\
\hline Native American & 4.03 \\
\hline Asian/Pacific Islander & 5.33 \\
\hline
\end{tabular}

Four theoretical models were analyzed. The first one predicted the probability of child overweight given the mother's BMI, weeks of breast feeding, and weight gain category according to the IOM gestational weight gain recommendations (2009). The second model included weeks of breastfeeding as a moderator of the other relations. The third model added ethnicity to the above predictors. And the last model, included ethnicity as the moderator of the other relations.

Table 2 presents the results for the first model. As is appropriate for generalized linear modeling, both prepregnancy $\mathrm{BMI}$ and weeks of breastfeeding were mean-centered, so that the intercept could be interpreted as a function of their average. The intercept OR represents the probability of child obesity when the mother has an average $\mathrm{BMI}$, average weeks of breast feeding, and ideal weight gain; with a $2.8 \%(95 \% \mathrm{Cl}=2 \%, 3 \%)$ chance of 
child obesity. Given the large sample, this study was considered over-powered; for this reason, the research team interpreted the effect size (OR) of each predictor variable to demonstrate the magnitude of the effects in the models.

Table 2. Model 1: logistic regression results for the outcome of early childhood obesity.

\begin{tabular}{|l|l|l|}
\hline & Estimate (SE) & OR (95\% Cl) \\
\hline Intercept & $-3.549(0.074)$ & $0.028(0.02,0.03)$ \\
\hline Mother BMI & $0.044(0.004)$ & $1.045(1.04,1.05)$ \\
\hline Weeks of BF & $0.019(0.004)$ & $1.019(1.01,1.03)$ \\
\hline Normal GWG & $-0.089(0.114)$ & $0.914(0.73,1.14)$ \\
\hline Excessive GWG & $0.406(0.088)$ & $1.501(1.26,1.78)$ \\
\hline
\end{tabular}

Holding weight gain and weeks of breastfeeding constant, as a mother's pre-pregnancy BMI increased by $1 \mathrm{~kg} / \mathrm{m}^{2}$, the odds of child obesity increased by $1.045(95 \% \mathrm{Cl}=1.04,1.05)$; an increase in $4.5 \%(95 \% \mathrm{Cl}=4.0 \%$, $5.0 \%)$ in the probability of obesity compared to children of mothers with normal pre-pregnancy weight. Holding pre-pregnancy BMI and gestational weight gain constant, as breastfeeding increased by 1 week, the odds of child obesity increased by $1.019(95 \% \mathrm{Cl}=1.01,1.03)$; an increase in $1.9 \%(95 \% \mathrm{Cl}=1 \%, 3 \%)$ in their probability of obesity.

Analysis of cases where the mother's weight gain was less than recommended by the IOM demonstrated no difference in probability of child obesity compared to the cases where the mothers had ideal weight gain (OR $=0.914,95 \% \mathrm{Cl}=0.73,1.14)$. This represents on average a decrease in the probability of child obesity of $8.6 \%(95 \% \mathrm{Cl} 26.8,14.2)$. Among mothers that gained more weight than recommended, the odds of child obesity increased by $1.50(95 \% \mathrm{Cl} 1.26,1.78)$; a $50 \%$ increase $(95 \% \mathrm{Cl}=26 \%, 78 \%)$ in their probability of child obesity compared to mothers with ideal weight gain, keeping mother BMI and weeks of breastfeeding constant.

Fig. 1 shows the results for the first model. With mother's pre-pregnancy BMI constant, probability of child obesity increased as weeks of breastfeeding increased; exhibiting a small effect. With weeks of breastfeeding constant, child obesity probability increased as the mother's pre-pregnancy BMI increased. These plots show the probabilities for participants with ideal weight gain, less than the ideal, and higher than ideal. Keeping weeks of breastfeeding and mother BMI constant, the participants with ideal weight gain did not differ from the participants with less than the ideal weight gain; the greater change in probability was for the participants that gain more weight than ideal. These participants have a higher probability of child obesity.
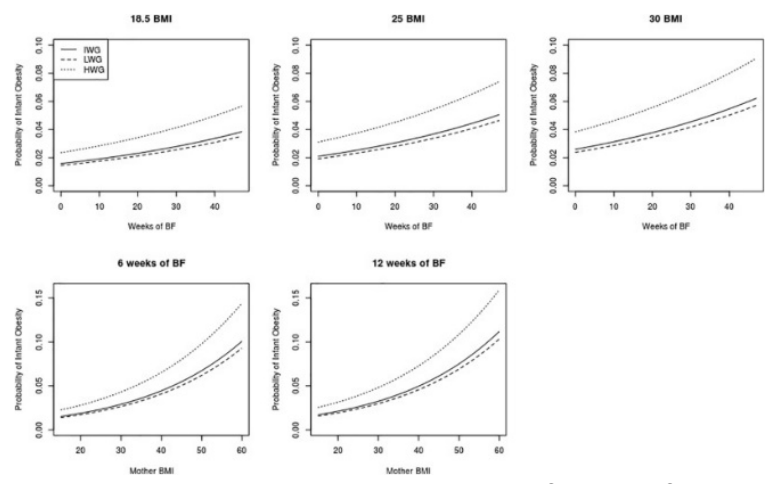

Fig. 1. Plots: mother BMI, weeks of breastfeeding, and weight gain.

Interactions between the predictor variables and weeks of breastfeeding were tested to determine whether predictor slopes change in function of the duration of breastfeeding. After probing and plotting these results, we concluded that the relations are not changed in function of duration of breastfeeding with a $p$-value criterion of 0.05 . 
For the third model (Fig. 2), the effects of maternal pre-pregnancy BMI, weeks of breast feeding, and weight gain follow the same pattern as the first model, and these are not different across ethnicity groups. We found that Black children were less likely to be obese than White children $(\mathrm{OR}=0.792 ; 95 \% \mathrm{Cl}=0.66,0.96)$. Both Hispanic children and the other group (Native American/multiple ethnicity) had an increased risk of child obesity compared to White children: OR $1.364(95 \% \mathrm{Cl}=1.16,1.60)$ and $\mathrm{OR} 1.404(95 \% \mathrm{Cl}=1.05,1.88)$ respectively. The Asian/Pacific Islander participants are as likely as the White children to be obese, $\mathrm{OR} 1.045(95 \% \mathrm{Cl}=0.75$, 1.45).

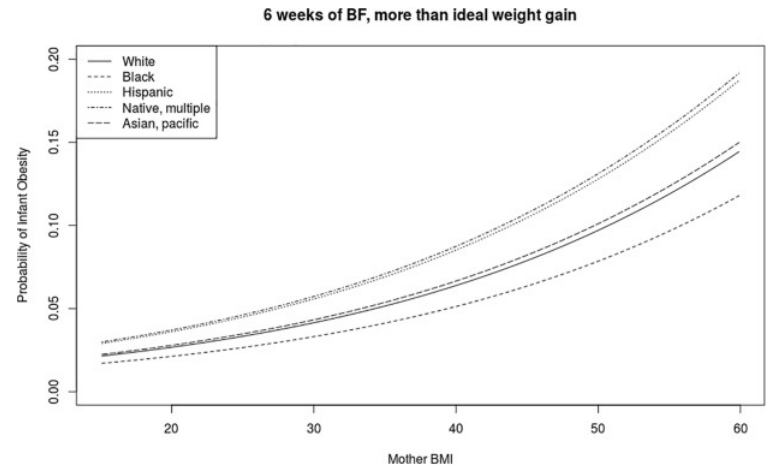

Fig. 2. Plots: differences by race/ethnicity.

Interactions between the predictor variables and ethnicity were tested to determine whether predictor slopes were different across ethnicity groups (Table 3). There were no meaningful interactions of ethnicity with the other predictors, tested by probing and plotting this moderation with a $p$-value criterion of 0.05 .

Table 3. Model 2: logistic regression results for the outcome of early childhood obesity, analyzed for differences by race.

\begin{tabular}{|l|l|l|}
\hline & Estimate (SE) & OR (95\% Cl) \\
\hline Intercept & $-3.602(0.082)$ & $0.027(0.02,0.03)$ \\
\hline Mother BMI & $0.045(0.004)$ & $1.046(1.03,1.06)$ \\
\hline Weeks of BF & $0.019(0.004)$ & $1.019(1.01,1.03)$ \\
\hline Normal GWG & $-0.085(0.114)$ & $0.918(0.73,1.15)$ \\
\hline Excessive GWG & $0.417(0.088)$ & $1.518(1.27,1.80)$ \\
\hline Ethnicity & & \\
\hline Black & $-0.233(0.095)$ & $0.792(0.66,0.96)$ \\
\hline Hispanic & $0.311(0.082)$ & $1.364(1.16,1.60)$ \\
\hline Native American & $0.339(0.147)$ & $1.404(1.05,1.88)$ \\
\hline Asian/Pacific Islander & $0.044(0.166)$ & $1.045(0.75,1.45)$ \\
\hline
\end{tabular}

\section{Discussion}

This is the only study to date to analyze a comprehensive model with maternal pre-pregnancy BMI, gestational weight gain, and breastfeeding. We found only maternal weight factors had a statistically significant relationship to child weight in the first 2 years after controlling for the other factors. Maternal weight factors are crucial in determining a child's risk of becoming overweight and developing obesity (Kaar et al. 2014; Tie et al. 2014).

In this study, breastfeeding did not have the hypothesized protective effect against early childhood obesity after accounting for maternal weight-related factors; and, in fact the opposite relationship emerged in these analyses: breastfeeding of short duration was associated with increased risk of early childhood obesity (Fig. 1). Additionally, in every weight category, this risk was highest among mothers who gained more than recommended for their pre-pregnancy $\mathrm{BMI}$, supporting the evidence that both pre-pregnancy weight and gestational weight gain are the strongest predictors of obesity risk up to age 1 year. Previous evidence for 
breastfeeding as a protective factor for childhood obesity among low-income families has been mixed, and there has been a wide variation in age of the children in the analyses, the duration of breastfeeding, and the populations.

Large data studies and systematic reviews have found a dose-related negative association between extended duration of exclusive breastfeeding and childhood overweight (Anderson et al. 2014; Grummer-Strawn and Mei 2004; Hess et al. 2015; Moss and Yeaton 2014). Like our study, one of these studies noted that there were variations in the effect of breastfeeding on childhood among racial sub-groups (Grummer-Strawn and Mei 2004). Overall, the evidence has supported breastfeeding as an intervention to promote healthy weight; however, these studies have not included important confounding factors that comprise weight-related risk to children.

Other studies that have accounted for other known childhood obesity risk factors such as SES in their analyses demonstrated no protective effect of breastfeeding (Etevez-Gonzalez et al., 2016; Victora et al. 2016). Studies that did find a protective effect of breastfeeding against child obesity found that the necessary duration of breastfeeding was a minimum of 2.5 months, with a range of 2.5 months -8 months of exclusive breastfeeding necessary to produce the protective effect (Hess et al. 2015; Moss and Yeaton 2014). The mean duration of breastfeeding among breastfed infants in our study was 5.58 weeks $(S D=7.1)$. It may be that the breastfeeding dose in this sample was not sufficient to provide protection against child obesity.

Additionally, most of the studies examining the effects of breastfeeding on child weight status have not included important confounding variables. In the study by Procter and Holcomb (2008) using Kansas WIC data from19982002 , longer duration of breastfeeding lowered the risk of childhood overweight at age 4 but there was no significant effect for breastfeeding after controlling for other obesity-related risk factors like race, environmental factors, and SES. Neither the Proctor and Holcomb study nor any other studies have examined the three factors of pre-pregnancy BMI, gestational weight gain, and breastfeeding behaviors.

Our study suggests that maternal weight and gestational weight gain have such a strong impact that breastfeeding of short duration does not protect a child against obesity in the first 2 years of life. In fact, among low-income women who were obese and/or who gained excessive weight in pregnancy, a short duration of breastfeeding may increase obesity risk. This highlights the importance of preventive health behavior education to promote physical activity and dietary practices that comprise weight management throughout the childbearing years, during pregnancy, and through the early parenting years.

In conclusion, healthcare providers should continue to intervene to support breastfeeding due to the many health benefits for mother and child (Bibbins-Domingo et al., 2016; Ostbye et al. 2010). However, the benefit of reducing early childhood obesity via breastfeeding is not supported by this study. If we are going to work toward an upstream solution to childhood obesity, we should focus efforts on behaviors women can change before and during pregnancy to potentially minimize the intrauterine exposures to maternal obesity and excessive pregnancy weight gain.

\subsection{Limitations}

Strengths of this study included a robust statistical analysis of a large, diverse sample. In particular, our use of WIC data ensured that we are examining these factors within a population of women and children most at risk for overweight, obesity, and the associated chronic health sequalae (Yang et al. 2017). However, there are limitations to note. This is a retrospective secondary data analysis. The data has already been collected, and the research team could not determine the variables and how they were operationalized. Additionally, there was missing data from some charts. We chose to impute the data to account for that potential threat to validity. 
Additionally, while the nurses and dieticians of the WIC program consistently record infant weight and length data and women's measured weights during pregnancy visits, maternal pre-pregnancy weight information is self-reported. Gestational weight gain is then calculated from this self-reported data. A recent systematic review and meta-analysis found that use of self-reported pre-pregnancy weight is a reliable manner of measuring this variable in research (Headen et al. 2017). Additionally, both breastfeeding duration and exclusivity were measured via self-report.

Two factors were unique to this sample that affect generalizability. First, the average duration of breastfeeding was quite low in this sample $(m=5.58, S D=7.14)$, and there were few women who breastfed beyond 12 weeks. The generalizability of findings regarding breastfeeding's impact on child weight are impacted by the low dose of breastfeeding that was received by infants in this dataset. Furthermore, future prospective research could use a more precise measure of breastfeeding than weeks, as was collected in this dataset. A more precise measure would offer a better understanding of dose and effect of breastfeeding on child weight. Second, because this was a statewide sample of WIC participants, the SES is lower than the state and national median. The results of this study may not be applicable to other, less vulnerable populations.

\section{Conclusion}

In this study, pre-pregnancy weight status and gestational weight gain were significantly associated with early childhood obesity risk among a sample of maternal-child dyads enrolled in the WIC program. In this sample, breastfeeding did not decrease the risk of early childhood obesity. These results provide a renewed call to primary care providers and pregnancy care providers to focus on evidence-based preventive health behaviors that will promote women's weight management throughout the childbearing years.

\section{Acknowledgments}

This research was supported by Wallace Funding through the Marquette University College of Nursing.

This publication was supported by the National Center for Research Resources and the National Center for Advancing Translational Sciences, National Institutes of Health, through Grant Number UL1TR001436. Its contents are solely the responsibility of the authors and do not necessarily represent the official views of the $\mathrm{NIH}$.

\section{References}

Agresti, A., 2007. An Introduction to Categorical Data Analysis, 2nd ed. Wiley-Interscience, Hoboken, NJ.

Anderson, J., Hayes, D., Chock, L., 2014. Characteristics of overweight and obesity at age two and the association with breastfeeding in Hawai'i women, infants, and children(WIC) participants. Matern. Child Health J. 18, 2323-2331.https://doi.org/10.1007/s10995-013-1392-9.

Andrea, S.B., Hooker, E.R., Messer, L.C., Tandy, T., Boone-Heinonen, J., 2017. Does the association between early life growth and later obesity differ by race/ethnicity or socioeconomic status? A systematic review. Ann. Epidemiol. 27 (9), 583-592.https://doi.org/10.1016/j.annepidem.2017.08.019.

Baraldi, A.N., Enders, C.K., 2010. An introduction to modern missing data analyses. J.School Psychol. 48 (1), 537. https://doi.org/10.1016/i.jsp.2009.10.001.

Bibbins-Domingo, K., Grossman, D.C., Curry, S.J., Davidson, K.W., Karina, W., Epling, J.W., ... Pignone, M.P., 2016. Primary care interventions to support breastfeeding: US preventive services task force recommendation statement. JAMA 316 (16). https://doi.org/10.1001/jama2016.14697.

Centers for Disease Control and Prevention (CDC), 2013. CDC health disparities and in-equalitites report, United States, 2013. MMWR 62 (3). 
Choirat, C., Honaker, J., Imai, K., King, G., Lau, O., 2017. Zelig: Everyone's Statistical Software. Version 5.1.5. URL:http://zeligproject.org/.

Darlington, R.B., Hayes, A.F., 2017. Regression Analysis and Linear Models. Concepts, Applications, and Implementation. The Guilford Press, New York, NY, US.

Enders, C.K., 2010. Applied Missing Data Analysis. Guilford Press, New York.

Etevez-Gonzalez, M.D., Santana del Pino, A., Henriquez-Sanchez, P., Pena-Quintana, L., Saavedra-Santana, P., 2016. Breastfeeding during the first 6 months of life, adiposity rebound and overweight/obesity at 8 years of age. Int. J. Obes. 40, 10-13. https://doi.org/10.1038/ijo.2015.228.

Gelman, A., Hill, J., 2007. Data analysis using regression and multilevel/hierarchical models. In: Analytical Methods for Social Research. Cambridge University Press, New York.

Goodell, L.S., Wakefield, D.B., Ferris, A.M., 2009. Rapid weight gain during the first year of life predicts obesity in 2-3 year olds from a low-income minority population. J.Commun. Health 34 (5), 370375.https://doi.org/10.1007/s10900-009-9164-6.

Gopinath, B., Subramanian, I., Flood, V.M., Baur, L.A., Pfund, N., Burlutsky, G., Mitchell,P., 2012. Relationship between breast-feeding and adiposity in infants and pre-schoolchildren. Public Health Nutr. 15 (9), 1639-1644.https://doi.org/10.1017/S1368980011003569.

Grummer-Strawn, L.M., Mei, Z., 2004. Does breastfeeding protect against pediatric overweight? Analysis of longitudinal data from the Centers for Disease Control and Prevention Pediatric Nutrition Surveillance System. Pediatrics 113 (2). Retrievedfrom: http://pediatrics.aappublications.org/content/113/2/e81.short?casa_token=LnSaiOGG7EAAAAA:P4kcK3ccj6ChhSw13HXb2nc_HEq3rIJJZvS7Dm7_Ny8p87iPkBI3RlaCxiJV19DlurthJtQwcA

Hales, C.M., Carroll, M.D., Fryar, C.D., Ogden, C.L., 2017. Prevalence of obesty among adults and youth: United States, 2015-2016. NCHS Data Brief 288 (Retrieved from: file://C:/Users/1194ohlendi/Downloads/cdc 49223 DS1.pdf).

Headen, I., Cohen, A.K., Mujahid, M., Abrams, B., 2017. The accuracy of self-reported pregnancy-related weight: a systematic review. Obes. Rev. 18 (3), 350-369.https://doi.org/10.1111/obr.12486.

Heerman, W.J., Bian, A., Shintani, A., Barkin, S.L., 2014. Interaction between maternal prepregnancy body mass index and gestational weight gain shapes infant growth. Acad. Pediatr. 14 (5), 463470.https://doi.org/10.1016/j.acap.2014.05.005.

Hess, C., Ofei, A., Mincher, A., 2015. Breastfeeding and childhood obesity among African Americans: a systematic review. MCN Am. J. Matern. Child Nurs. 40 (5), 313319.https://doi.org/10.1097/NMC.0000000000170.

Honaker, J., King, G., Blackwell, M., 2011. Amelia II: a program for missing data. J. Stat. Softw. 45 (7), 1-47. URL. http://www.jstatsoft.org/v45/i07/.

Institute of Medicine, 2009. Weight Gain During Pregnancy: Reexamining the Guidelines. Retrieved from. http://www.iom.edu/en/Reports/2009/Weight-Gain-During-Pregnancy-Reexamining-theGuidelines.aspx.

Kaar, J.L., Crume, T., Brinton, J.T., Bischoff, K.J., McDuffie, R., Dabelea, D., 2014.Maternal obesity, gestational weight gain, and offspring adiposity: the exploring perinatal outcomes among children study. J. Pediatr. 165, 509-515.https://doi.org/10.1016/jpeds.2014.05.050.

Karnon, J., Ali Afzali, H.H., Gray, J., Holton, C., Banham, D., Beilby, J., 2013. A risk-adjusted cost-effectiveness analysis of alternative models of nurse involvement in obesity management in primary care. Obesity 21 (3), 472-479.https://doi.org/10.1002/oby.20100.

Lamb, M.M., Dabelea, D., Yin, X., Ogden, L.G., Klingensmith, G.J., Rewers, M., Norris,J.M., 2010. Early-life predictors of higher body mass index in healthy children. Ann.Nutr. Metab. 56, 16-22. https://doi.org/10.1159/000261899. 
Langley-Evans, S.C., 2014. Nutrition in early life and the programming of adult disease: areview. J. Hum. Nutr. Diet. 28 (Suppl. 1), 1-14. https://doi.org/10.1111/ihn.12212.

Lefebvre, C.M., John, R.M., 2014. The effect of breastfeeding on childhood overweight and obesity: a systematic review of the literature. J. Am. Assoc. Nurse Pract. 26 (7),386-401.https://doi.org/10.1002/23276924.12036.

Margerison Zilko, C.E., Rehkopf, D., Abrams, B., 2010. Am. J. Obstet. Gynecol. 202 (6), 574.https://doi.org/10.1016/j.ajog.2009.12.007.(e1-8).

McCormick, D.P., Sarpong, K., Jordan, L., Ray, L.A., Jain, S., 2010. Infant obesity: are we ready to make this diagnosis? J. Pediatr. 157 (1), 15-19. https://doi.org/10.1016/i.jpeds.2010.01.028.

Moss, B.G., Yeaton, W.H., 2014. Early childhood healthy and obese weight status: potentially protective benefits of breastfeeding and delaying solid foods. Matern. Child. Health J. 18 (5), 12241232.https://doi.org/10.1007/s10995-013-1357-z.

Norris, S.A., Osmond, C., Gigante, D., Kuzawa, C.W., Ramakrishnan, L., Lee, N.R., ... Fall,C.H., 2012. Size at birth, weight gain in infancy and childhood and adult diabetes risk in five low- or middle-income country birth cohorts. Diabetes Care 35 (1), 72-79.https://doi.org/10.2337/dc11-0446.

Ogden, C.L., Carroll, M.D., Kit, B.K., Flegal, K.M., 2014. Prevalence of childhood and adult obesity in the United States, 2011-2012. JAMA 311 (8), 806-814.https://doi.org/10.1001/jama.2014.732.

Ostbye,T., Krause, K.M., Swamy, G.K., Lovelady, C.A., 2010. Effect of breastfeeding on weight retention from one pregnancy to the next: results from the North Carolina WIC Program. Prev. Med. 51, 368372.https://doi.org/10.1016/j.ypmed.2010.07.017.

Pelone, F., Specchia, M.L., Veneziano, M.A., Capizzi, S., Bucci, S., Mancuso, A., de Belvis, A.G., 2012. Economic impact of childhood obesity on health systems: a systematic review. Obes. Rev. 13, 431440.https://doi.org/10.1111/j.1467-789X.2011.00968.x.

Procter, S.B., Holcomb, C.A., 2008. Breastfeeding duration and childhood overweight among low-income children in Kansas, 1998-2002. Am. J. Public Health 98 (1),106110.https://doi.org/10.2105/AJPH.2006.101683.

Pulgaron, E.R., 2013. Childhood obesity: a review of increased risk for physical and psychological comorbidities. Clin. Ther. 35 (1), A18-A32.https://doi.org/10.1016/j.clinthera.2012.12.014.

R Core Team, 2017. R: A Language and Environment for Statistical Computing. R Foundation for Statistical Computing, Vienna, Austria URL.https://www.R-project.org/.

Rubin, D.B., 1987. Multiple Imputation for Nonresponse in Surveys. Wiley, New York.

Santos, J.L., Kain, J., Dominguez-Vasquez, P., Lera, L., Galvan, M., Corvalan, C., Uauy, R.,2009. Int. J. Behav. Nutr. Phys. Act. 6, 93.https://doi.org/10.1186/1479-5868-6-93.

Shankaran, S., Bann, C., Das, A., Lester, B., Bada, H., Bauer, C.R., La Gasse, L., Higgins,R.D., 2011. Risk for obesity in adolescence starts in early childhood. J. Perinatol. 31,711-716.https://doi.org/10.1038/jp.2011.14.

Streuling, I., Beyerlein, A., von Kries, R., 2010. Can gestational weight gain be modified by increasing physical activity and diet counseling? A meta-analysis of interventional trials. Am. J. Clin. Nutr. 92 (4), 678-687. https://doi.org/10.3945/ajcn.2010.29363.

Tie, H.-T., Xia, Y.-Y., Zeng, Y.-S., Zhang, Y., Dai, C.-L., Guo, J.J., Zhao, Y., 2014. Risk of childhood overweight or obesity associated with excessive weight gain during pregnancy: a meta-analysis. Arch. Gynecol. Obstet. 289, 247-257.https://doi.org/10.1007/s00404-013-3053-z.

Tomar, A.S., Tallapragada, D.S., Nongmaithem, S.S., Shrestha, S., Yajnik, C.S., Chandak,G.R., 2015. Intrauterine programming of diabetes and adiposity. Curr. Obes. Rep. 4(4), 418-428.https://doi.org/10.1007/s13679015-0175-6.

Trasande, L., Chatterjee, S., 2012. The impact of obesity on health service utilization andcosts in childhood. Obesity 17 (9). https://doi.org/10.1038/oby.2009.67. 
U. S. Department of Health \& Human Services, Office of Disease Prevention and Health Promotion, 2014.

Leading Health Indicators: Nutrition, Physical Activity, and Obesity. Retrieved from:

https://www.healthypeople.gov/2020/leading-health-indicators/2020-Ihi-topics/Nutrition-PhysicalActivity-and-Obesity/determinants.

Umer, A., Hamilton, C., Britton, C.M., Mullett, M.D., John, C., Neal, W., Lilly, C.L., 2015.Association between breastfeeding and childhood obesity: analysis of a linked longitudinal study of rural Appalacian fifthgrade children. Child. Obes. 11 (4), 449-455.https://doi.org/10.1089/chi.2015.0026.

van Dijk, S.J., Tellam, R.L., Morrison, J.L., Muhlhausler, B.S., Molloy, P.L., 2015. Recent developments on the role of epigenetics in obesity and metabolic disease. Clin.Epigenetics11 (7).https://doi.org/10.1186/s13148015-0101-5.

Victora, C.G., Bahal, R., Barros, A.J., Gioavnny, V.A., Franca, S.H., Krasever, J., ... Rollins,N.C., 2016. Breastfeeding in the 21st century: epidemiology, mechanisms, and life-long effect. Lancet 387, 475490.https://doi.org/10.1016/S0140-6736(15)01024-7.

Wallander, J.L., Taylor, W.C., Grunbaum, J.A., Franklin, F.A., Harrison, G.G., Kelder,S.H., Schuster, M.A., 2012. Weight status, quality of life, and self-concept in African American, Hispanic, and White fifth-grade children. Obesity 17 (7).https://doi.org/10.1038/oby.2008.668.

Yang, Y.C., Johnson, M.P., Schorpp, K.M., Boen, C.E., Harris, K.M., 2017. Young adult risk factors for cancer: obesity, inflammation, and sociobehavioral mechanisms. Am. J.Prev. Med. 53 (3S1), S21S29.https://doi.org/10.1016/j.amepre.2017.04.025.J.M. Ohlendorf et al.Preventive Medicine 118 (2019) 210-215215 